\title{
Astroglial Knockout of Glucocorticoid Receptor Attenuates Morphine Withdrawal Symptoms, but Not Antinociception and Tolerance in Mice
}

\author{
Magdalena Tertil $^{1} \cdot$ Urszula Skupio ${ }^{2} \cdot$ Lucja Kudla $^{2} \cdot$ Lucja Wiktorowska $^{2} \cdot$ Ryszard Przewlocki $^{2}$ (I)
}

Received: 23 December 2020 / Accepted: 24 March 2021 / Published online: 5 April 2021

(c) The Author(s) 2021

\begin{abstract}
The development of tolerance and drug dependence limit the clinical application of opioids for the treatment of severe pain. Glucocorticoid receptors (GRs) are among molecular substrates involved in these processes. Most studies focus on the role of neuronal GR, while the involvement of GR on glial cells is not fully understood. To address this issue, we used a transgenic model of conditional GR knockout mice, targeted to connexin 30-expressing astrocytes, treated with repeated doses of morphine. We observed no difference between control mice and astrocytic GR knockouts in the development of antinociceptive tolerance. Nevertheless, when animals were subjected to precipitated withdrawal, knockouts presented some attenuated symptoms, including jumping. Taken together, our data suggest that hippocampal and spinal astrocytic GRs appear to be involved in opioid withdrawal, and drugs targeting the GR may relieve some symptoms of morphine withdrawal without influencing its antinociceptive properties.
\end{abstract}

Keywords Astrocytes · Glucocorticoid receptor $\cdot$ Morphine withdrawal $\cdot$ Morphine tolerance

Opioids are frequently used drugs in the clinical management of severe pain. However, their application is limited by the development of analgesic tolerance and drug dependence following prolonged or repeated use. Accumulating evidence suggests that glucocorticoid receptors (GRs) are involved in the antinociceptive action of the drug and play a role in opioid-induced analgesia and tolerance [Wong et al. 1982, Lim et al. 2005a, Navarro-Zaragoza et al. 2012]. Most of the studies focus on mechanisms related to the neuronal GR, while the role of GR on glial cells is not fully understood, although there are clear indications of the involvement of GR-responsive genes, such as aquaporin 4 and serum and glucocorticoid-regulated kinase 1 in astrocytes in these

Magdalena Tertil and Urszula Skupio contributed equally as first authors

Ryszard Przewlocki

nfprzewl@cyf-kr.edu.pl

1 Laboratory of Pharmacology and Brain Biostructure, Department of Pharmacology, Maj Institute of Pharmacology Polish Academy of Sciences, Krakow, Poland

2 Department of Molecular Neuropharmacology, Maj Institute of Pharmacology Polish Academy of Sciences, ul. Smetna 12, 31-343 Krakow, Poland processes [Wu et al. 2008, Xiao et al. 2019]. Our previous research demonstrated that astrocytes are a major cellular target of the transcriptional component of morphine action via GR [Slezak et al. 2013] and that astrocytic GR activation is involved in morphine reward [Skupio et al. 2020]. Yet it has not been investigated whether both glial cells and GRs may play a role in opioid-induced antinociception and tolerance/withdrawal.

To address these questions, we have employed a murinetargeted GR knockout model. The conditional astrocytic deletion of GR was achieved by crossing GR flox/flox animals with a transgenic strain expressing CreERT2 under connexin-30 promoter ( $\left.\mathrm{GR}^{\mathrm{astroKO}}\right)$, as previously described [Tertil et al. 2018]. The mRNA levels of GR in the lumbar spinal cord (SC) were reduced by approximately $30 \%$ within the whole tissue lysate, indicating a high inactivation of the GR allele in this area in comparison with other regions of the central nervous system (Fig. 1a). It was further corroborated by the pattern of induction of a GR-targeted gene Fkbp 5 after the injection of a GR agonist dexamethasone (Dex), which was reduced by over $60 \%$ in the spinal cord (Fig. 1b). The amygdala and hippocampus also showed an impaired GR transcriptional response, confirming the previously presented validation of the model [Tertil et al. 2018]. Importantly, when we measured the regulation of an 

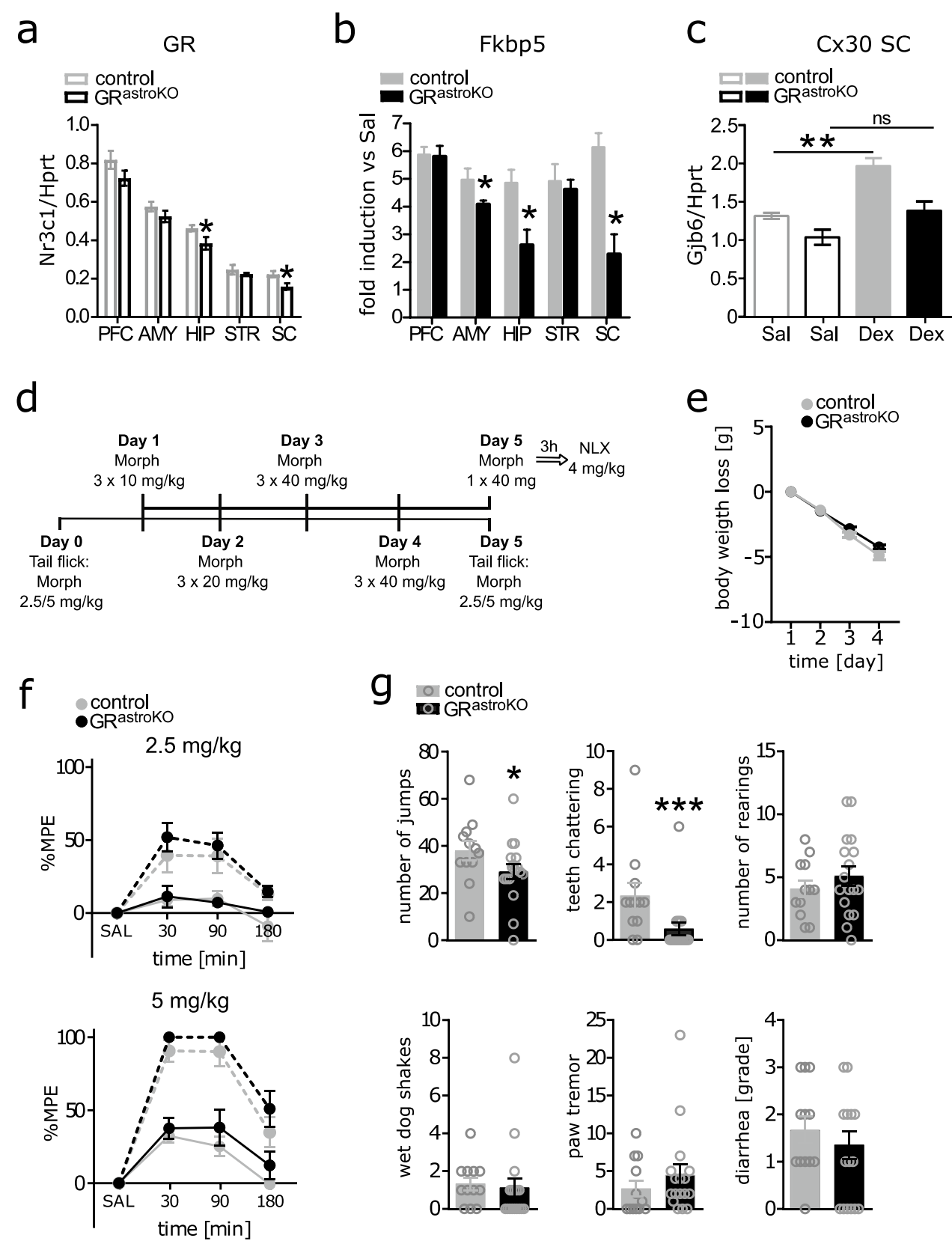

Fig.1 a Expression of $\mathrm{Nr} 3 \mathrm{cl}$ (GR) mRNA normalized to reference gene Hprt determined by real-time qPCR in prefrontal cortex (PFC, $\mathrm{t}_{6}=1.56, p=0.09$ ), amygdala (AMY, $\left.\mathrm{t}_{6}=1.32, p=0.12\right)$, hippocampus (HIP, $\mathrm{t}_{6}=2.17, p=0.04$ ), striatum (STR, $\mathrm{t}_{6}=0.89, p=0.21$ ), and lumbar spinal cord $\left(\mathrm{SC}, \mathrm{t}_{6}=2.73, p=0.02\right)$ of control $(n=4)$ and GR knockout $(n=4)$ animals. b Relative induction of GR target gene Fkbp5 (PFC: $\mathrm{t}_{7}=0.13 \mathrm{p}=0.45 ;$ AMY: $\mathrm{t}_{7}=2.29 p=0.03$; HIP: $\mathrm{t}_{7}=2.99 p=0.01 ;$ STR: $\left.\mathrm{t}_{7}=0.43 p=0.34 ; \mathrm{SC}: \mathrm{t}_{7}=4.16 p=0.002\right)$ in different regions of the central nervous system $4 \mathrm{~h}$ following i.p. injection of $4 \mathrm{mg} / \mathrm{kg}$ GR agonist dexamethasone: qPCR data normalized by $\Delta \Delta \mathrm{Ct}$ method to control animals receiving saline. $\mathbf{c}$ Regulation of transcription of $\mathrm{Cx} 30$ in lumbar SC following treatment with Dex (as in b) - levels of Gjb6 mRNA normalized to reference gene Hprt determined by real-time qPCR (genotype effect: $\mathrm{F}_{1,12}=17.42$, $p<0.001$; treatment effect: $\left.\mathrm{F}_{1,12}=20.72, p<0.001\right)$. d Scheme of the administration of morphine for the investigation of naloxoneprecipitated withdrawal and drug tolerance. e Body weight loss during each day of morphine administration in control and GR knockout mice ( $n=19 /$ genotype, time effect $\mathrm{F}_{3,114}=451, p<0.001$, genotype effect insignificant). f Results of tail-flick test (maximum possible effect- \%MPE) - antinociceptive effect of two doses of morphine $\left(n=10 /\right.$ genotype for $2.5 \mathrm{mg} / \mathrm{kg}, \mathrm{F}_{7,126}=0.32, p=0.94$, time effect: $\mathrm{F}_{7,126}=16.74, p<0.001$, genotype effect insignificant; $n=9 /$ genotype for $5 \mathrm{mg} / \mathrm{kg}, \mathrm{F}_{7,112}=0.46, p=0.86$, time effect: $\mathrm{F}_{7,112}=75.71$, $p<0.001$, genotype effect insignificant) after acute (dotted lines) and chronic (solid lines) administration of the drug. g Evaluation of symptoms of precipitated withdrawal in control $(n=12)$ and GR knockout $(n=17)$ mice (jumps: $\mathrm{U}=55, p=0.03$ teeth chattering: $\mathrm{U}=35, p<0.001$; rearings: $\mathrm{t}_{27}=0.96, p=0.34$; wet dog shakes: $\mathrm{U}=71, p=0.15$; paw tremor: $\mathrm{U}=76, p=0.25$; diarrhea: $\mathrm{U}=85.5$, $p=0.45)$. All data represent mean \pm SEM. $(\mathbf{a}, \mathbf{b}, \mathbf{g})$ Unpaired Student's t-test or Mann-Whitney test (when data distribution did not pass Anderson-Darling normality test), (c) two-way ANOVA followed by Bonferroni post hoc analysis; $(\mathbf{e}, \mathbf{f})$ two-way repeated measures ANOVA 
astrocyte-specific GR target gene Gjb6 (coding for Cx30) in the lumbar SC, no significant upregulation could be observed in $\mathrm{GR}^{\text {astroKO }}$ animals injected with Dex, indicating the efficient inactivation of the GR-dependent transcriptional response within this cell type (Fig. 1c).

To model chronic morphine exposure, mice received 3 daily injections of the drug in increasing doses for 4 days (Fig. 1d). We noted similar weight loss in both control and $\mathrm{GR}^{\text {astroKO }}$ mice (Fig. 1e). To investigate the development of tolerance, pain responses after a $2.5 \mathrm{mg} / \mathrm{kg}$ or $5 \mathrm{mg} / \mathrm{kg}$ morphine injection were measured one day prior to and one day after the chronic morphine administration (Fig. 1d). Baseline tail-flick measurements were performed 15 min before the morphine injection and confirmed no differences between genotypes in basal pain sensitivity already demonstrated in our previous study [Tertil et al. 2018]. The animals were tested for antinociception 30, 90, and 180 min after a single i.p. morphine administration (Analgesia Meter; Ugo Basile). Both control and $\mathrm{GR}^{\text {astroKO }}$ mice presented similar analgesic responses to the two different doses of morphine tested (Fig. 1f). The chronic administration of the drug resulted in the development of tolerance to its antinociceptive action in both groups of animals regardless of the genotype. This is in contrast to previously published data, which showed that non-cell type-specific blocking of spinal GR by inhibition of its expression or co-infusion of the receptor antagonist attenuated this phenomenon [Lim et al. 2005b, Zhai et al. 2018]. Thus, our data suggest that GR-dependent transcriptional responses to morphine in Cx30-positive astroglia are not involved in the development of tolerance to the drug, pointing rather to a neuron-dependent mechanism.

Another crucial limitation in the clinical application of morphine-based analgesics is the development of physical dependence, and GR has been widely implicated as one of the molecular substrates of addictive properties of drugs of abuse. Therefore, we next tested naloxone-precipitated opioid withdrawal symptoms after chronic morphine treatment (scheme as in Fig. 1d) in our transgenic model using previously described protocol [Parkitna et al. 2012]. Salinereceiving control groups were not introduced as it has been already demonstrated that saline-treated mice do not develop withdrawal syndrome [Solecki et al. 2019]. On the last day, mice received a single injection of $40 \mathrm{mg} / \mathrm{kg}$ morphine followed by an injection of naloxone $(4 \mathrm{mg} / \mathrm{kg})$ after $3 \mathrm{~h}$ and withdrawal symptoms were evaluated immediately. Jumping and teeth chattering were significantly decreased in $\mathrm{GR}^{\text {astroKo }}$ mice (Fig. 1g). This attenuation of the somatic expression of withdrawal directly confirms a role of astrocytic GR in morphine addiction that could be hypothesized from previous studies utilizing the non-specific inhibition of glial cell metabolism or pharmacological antagonists of GR [NavarroZaragoza et al. 2012, Seyedaghamiri et al. 2018]. It has to be noted that other withdrawal symptoms remained similar in both control and $\mathrm{GR}^{\text {astroKO }}$ mice, which may perhaps be due to the limited efficiency of our Cx30-CreERT2-driven knockout model, as demonstrated by the gene expression data. Spinal cord-associated jumping was attenuated while rearing, wet dog shakes and paw tremor were not significantly altered. The observed effects could also be at least partly associated with GRs localized in Cx30-positive glia in the hippocampus, where the targeting of our model is evident [Tertil et al. 2018], in line with the observations of Seyedaghamiri (2018) showing effects of local glial inhibition in the CA1 region.

Given the postulated role of neuronal GR in opiate addiction, our data suggest that general, non-cell type-specific inhibition of GR may be the right strategy to ameliorate the aversive symptoms of opiate withdrawal.

Acknowledgements The authors would like to acknowledge Maria Kaczmarczyk and Łukasz Szumiec for maintaining and genotyping transgenic mice.

Authors' Contributions MT and US contributed equally as first authors. MT designed, performed, and analyzed biochemical experiments and wrote the manuscript. US designed, performed, and analyzed behavioral experiments. LK and LW performed and analyzed behavioral experiments. RP designed and supervised the study. All authors critically reviewed the manuscript.

Funding This work was supported by grant 2013/08/A/NZ3/00848 from the Polish National Science Centre (awarded to RP) and the statutory and open access publication funds from the Maj Institute of Pharmacology Polish Academy of Sciences.

Data Availability The datasets used and/or analyzed during the current study are available from the corresponding author on reasonable request.

Code Availability Not applicable.

\section{Declarations}

Conflict of interest The authors declare that they have no competing interests.

Ethical Approval All experiments involving animals were approved by the II Local Ethics Committee (Decision No. 1156/2015) of the Maj Institute of Pharmacology.

Consent to Participate Not applicable.

Consent for Publication Not applicable.

Open Access This article is licensed under a Creative Commons Attribution 4.0 International License, which permits use, sharing, adaptation, distribution and reproduction in any medium or format, as long as you give appropriate credit to the original author(s) and the source, provide a link to the Creative Commons licence, and indicate if changes were made. The images or other third party material in this article are included in the article's Creative Commons licence, unless indicated 
otherwise in a credit line to the material. If material is not included in the article's Creative Commons licence and your intended use is not permitted by statutory regulation or exceeds the permitted use, you will need to obtain permission directly from the copyright holder. To view a copy of this licence, visit http://creativecommons.org/licenses/by/4.0/.

\section{References}

Lim G, Wang S, Zeng Q, Sung B, Mao J (2005a) Evidence for a long-term influence on morphine tolerance after previous morphine exposure: Role of neuronal glucocorticoid receptors. Pain 114:81-92

Lim G, Wang S, Zeng Q, Sung B, Mao J (2005b) Spinal glucocorticoid receptors contribute to the development of morphine tolerance in rats. Anesthesiology 102(4):832-837

Navarro-Zaragoza J, Hidalgo JM, Laorden ML, Milanés MV (2012) Glucocorticoid Receptors Participate in the Opiate WithdrawalInduced Stimulation of Rats NTS Noradrenergic Activity and in the Somatic Signs of Morphine Withdrawal. Br J Pharmacol 166(7):2136-2147

Parkitna JR, Solecki W, Gołembiowska K, Tokarski K, Kubik J, Gołda S, Novak M, Parlato R, Hess G, Sprengel R, Przewłocki R (2012) Glutamate Input to Noradrenergic Neurons Plays an Essential Role in the Development of Morphine Dependence and Psychomotor Sensitization. Int J Neuropsychopharmacol 15(10):1457-1471

Seyedaghamiri F, Heysieattalab S, Hosseinmardi N, Janahmadi M, Elahi-Mahani A, Salari F, Golpayegani M, Khoshbouei H (2018) Hippocampal Glial Cells Modulate Morphine-Induced Behavioral Responses. Physiol Behav 191:37-46

Skupio U, Tertil M, Bilecki W, Barut J, Korostynski M, Golda S, Kudla L, Wiktorowska L, Sowa JE, Siwiec M, Bobula B, Pels K, Tokarski K, Hess G, Ruszczycki B, Wilczynski G, Przewlocki R (2020)
Astrocytes determine conditioned response to morphine via glucocorticoid receptor-dependent regulation of lactate release. Neuropsychopharmacology 45(2):404-415

Slezak M, Korostynski M, Gieryk A, Golda S, Dzbek J, Piechota M, Wlazlo E, Bilecki W, Przewlocki R (2013) Astrocytes are a neural target of morphine action via glucocorticoid receptor dependent signaling. Glia 61(4):623-635

Solecki WB, Kus N, Gralec K, Klasa A, Pradel K, Przewłocki R (2019) Noradrenergic and corticosteroid receptors regulate somatic and motivational symptoms of morphine withdrawal. Behav Brain Res 360:146-157

Tertil M, Skupio U, Barut J, Dubovyk V, Wawrzczak-Bargiela A, Soltys Z, Golda S, Kudla L, Wiktorowska L, Szklarczyk K, Korostynski M, Przewlocki R, Slezak M (2018) Glucocorticoid receptor signaling in astrocytes is required for aversive memory formation. Transl Psychiatry 8(1):255

Wong CL, Wai MK (1982) The effect of adrenalectomy on the development of morphinetolerance and physical dependence in mice. Clin Exp Pharmacol Physiol 9(1):107-11

Wu N, Lu XQ, Yan HT, Su RB, Wang JF, Liu Y, Hu G, Li J (2008) Aquaporin 4 Deficiency Modulates Morphine Pharmacological Actions. Neurosci Lett 448(2):221-5

Xiao L, Han X, Wang XE, Li Q, Shen P, Liu Z, Cui Y, Chen Y (2019) Spinal Serum- and Glucocorticoid-Regulated Kinase 1 (SGK1) Signaling Contributes to Morphine-Induced Analgesic Tolerance in Rats. Neuroscience 413:206-218

Zhai ML, Chen Y, Liu C, Wang JB, Yu YH (2018) Spinal glucocorticoid receptor-regulated chronic morphine tolerance may be through extracellular signal-regulated kinase 1/2. Mol Med Rep 18(1):1074-1080

Publisher's Note Springer Nature remains neutral with regard to jurisdictional claims in published maps and institutional affiliations. 